\title{
Anti-cancer and potential chemopreventive actions of ginseng by activating Nrf2 (NFE2L2) anti-oxidative stress/anti-inflammatory pathways
}

\author{
Constance Lay-Lay Saw ${ }^{1,2^{*}}$, Qing Wu ${ }^{1,2,3}$, Ah-Ng Tony Kong ${ }^{1,2^{*}}$
}

\begin{abstract}
This article reviews recent basic and clinical studies of ginseng, particularly the anti-cancer effects and the potential chemopreventive actions by activating the transcriptional factor, nuclear factor (erythroid-derived 2)-like 2 (Nrf2 or NFE2L2)-mediated anti-oxidative stress or anti-inflammatory pathways. Nrf2 is a novel target for cancer prevention as it regulates the antioxidant responsive element (ARE), a critical regulatory element in the promoter region of genes encoding cellular phase II detoxifying and anti-oxidative stress enzymes. The studies on the chemopreventive effects of ginseng or its components/products showed that Nrf2 could also be a target for ginseng's actions. A number of papers also demonstrated the anti-inflammatory effects of ginseng. Targeting Nrf2 pathway is a novel approach to the investigation of ginseng's cancer chemopreventive actions, including some oxidative stress and inflammatory conditions responsible for the initiation, promotion and progression of carcinogenesis.
\end{abstract}

\section{Background}

Ginseng protects the cardiovascular system, stimulates the central nervous system [1] and possesses anti-cancer activities [2,3] inhibiting human gastric adenocarcinoma [4] and human breast carcinoma [5]. Therefore, ginseng is a potential cancer preventive agent [6].

Nuclear factor (erythroid-derived 2)-like 2 (Nrf2 or NFE2L2) is a key regulator of the antioxidant responsive element (ARE)-mediated gene expression and therefore a potential anti-cancer target for chemopreventive compounds [7], including ginseng [8-10]. However, concerns have been raised for possible inappropriate claims of ginseng products $[11,12]$. This article reviews the potential chemopreventive actions of ginseng via the Nrf2 signalling pathway and the potential molecular mechanism of ginseng's anti-cancer effects.

\section{Literature search}

A full literature search (up to 2010) was conducted during November 2009 till April 2010 with 'ginseng' as the search keyword was performed in PubMed and the Chinese National Knowledge Infrastructure (CNKI). Other

\footnotetext{
* Correspondence: constancesaw@gmail.com; kongt@pharmacy.rutgers.edu ${ }^{1}$ Center for Cancer Prevention Research, Ernest Mario School of Pharmacy, Rutgers, the State University of New Jersey, USA

Full list of author information is available at the end of the article
}

keywords used in the search included 'ginseng', 'Nrf2', 'chemoprevention', 'cancer prevention', 'clinical studies' and 'anti-cancer'. A total of 3917 and 147 papers from PubMed and CNKI respectively were retrieved and screened for anti-cancer clinical studies with ginseng. Seven published articles were found in PubMed with the keywords 'ginseng' and 'Nrf2' including a paper on Angelica sinensis (Danggui) [13].

\section{Ginseng in Chinese medicine}

In Chinese medicine, a disorder is often a manifestation of an imbalance between yin and yang and/or changes in the pathogenic and antipathogenic qi. Ginseng is the drug of choice for replenishing $q i$, especially in the case of $q i$ collapse. Major Chinese medicinal uses of ginseng and its commercial products and their indications are provided in Table 1.

Clinical studies on ginseng as adjuvant therapy for cancer Ginseng possesses preventive and therapeutics effects on cancer $[14,15]$. Ginseng is used to treat cancer or to reinforce the effects and/or reduce the side effects of chemotherapy [16,17]. Ginseng polysaccharides and ginsenosides are the main ingredients contributing to anticancer action of ginseng [18-21]. Ginseng boosts the patient's immunity, suppresses the proliferation of 
Table 1 Use of ginseng in Chinese medicine

\begin{tabular}{|c|c|c|}
\hline Actions & Indications & Chinese medicine products \\
\hline $\begin{array}{l}\text { To replenish the } \\
\text { primordial qi }\end{array}$ & $\begin{array}{l}\text { Collapse due to prostration of primordial qi, exhibiting extremely cold } \\
\text { limbs, sweating, vertigo and shortness of breath. }\end{array}$ & $\begin{array}{l}\text { Shenfu tang - decoction of ginseng and Aconiti } \\
\text { Lateralis; } \\
\text { Sinijia renshen tang - decoction of ginseng for } \\
\text { treating yang exhaustion. }\end{array}$ \\
\hline $\begin{array}{l}\text { To nourish the spleen } \\
\text { and stomach }\end{array}$ & $\begin{array}{l}\text { Spleen and stomach qi deficiency complicated by dampness, exhibiting } \\
\text { weakness of limbs, emaciation, indigestion, vomiting or diarrhoea, } \\
\text { fullness in the epigastrium and chest. }\end{array}$ & $\begin{array}{l}\text { Shenlingbaizhu san - powder of ginseng, Poria } \\
\text { and Atractylodis Macrocephalae; } \\
\text { Jianpi wan - pills for strengthening the spleen. }\end{array}$ \\
\hline $\begin{array}{l}\text { To promote the } \\
\text { production of body } \\
\text { fluid }\end{array}$ & $\begin{array}{l}\text { Impairment of both qi and yin, exhibiting lassitude, shortness of breath, } \\
\text { excessive perspiration, dry throat, thirst; also for long-standing cough } \\
\text { due to lung deficiency. }\end{array}$ & $\begin{array}{l}\text { Shengmai yin - liquid of ginseng, Radix } \\
\text { Ophiopogonis and Fructus Schisandrae for } \\
\text { restoring the pulse. }\end{array}$ \\
\hline $\begin{array}{l}\text { To invigorate the } \\
\text { spleen and nourish } \\
\text { the heart }\end{array}$ & $\begin{array}{l}\text { Disorders involving heart and spleen deficiency, exhibiting palpitation, } \\
\text { amnesia, insomnia, poor appetite, fatigue; also for cases of hemafecia, } \\
\text { metrorrhagia and metrostaxis. }\end{array}$ & $\begin{array}{l}\text { Guipi wan - ginseng pills for invigorating spleen } \\
\text { and nourishing the heart; } \\
\text { Renshen yangrong wan - pills of ginseng for } \\
\text { nourishing qi and yin. }\end{array}$ \\
\hline
\end{tabular}

tumour cells, inhibits the formation of new blood vessels in tumours, induces apoptosis of tumour cells, antimetastasis of tumour and immunomodulation $[3,6]$. Additional file 1 lists recent clinical studies of ginseng products as adjuvant therapy to chemotherapy and radiotherapy in China [22-27].

\section{Significance of the Nrf2-ARE signalling pathway in cancer chemoprevention}

Carcinogenesis involves multiple steps including transition of normal cells to pre-initiated cells and ultimately invasive carcinoma, providing ample opportunities for chemoprevention. In general, tumour development follows three distinct yet closely interrelated phases (I-III), namely initiation, promotion and progression $[28,29]$. When cells are exposed to oxidative stress, DNA may go through oxidative damage [30] coupled with persisting inflammation [31] as well as formation of DNA adducts, leading to increased genomic instability, enhanced neoplastic transformation and ultimately cancer (Figure 1). Various cancer chemopreventive compounds, including natural dietary and synthetic compounds, are found to be effective in preventing cancer formation at all of these three developmental stages [32-34] (Figure 1). Curcumin is one of such natural dietary chemopreventive compounds with promising findings from clinical trials $[35,36]$. When the cell is exposed to oxidative stress such as reactive oxygen species (ROS), reactive nitrogen species (RNS) or carcinogenic species, induction of phase I, phase II and phase III enzymes/transporters occur $[37,38]$. Carcinogens are typically metabolized via oxidation and reduction by phase I enzymes [39]. The resulting products are conjugated with endogenous cofactors such as glutathione (GSH) by glutathione $S$-transferase (GST), a phase II enzyme forming water soluble products that can be easily excreted $[39,40]$. Induction of other phase II enzymes such as uridine-diphospho-glucuronosyltransferases (UGT) may also enhance the excretion of carcinogens such as heterocyclic aromatic amines, the well-known genotoxic chemicals formed during preparation of foods $[41,42]$.

The induction of phase II enzymes can be attributed to the transcriptional control of the ARE by Nrf2 [7]. $\mathrm{Nrf} 2$ is a key regulator of ARE-mediated gene expression and a potential target for chemopreventive compounds [43-45]. Nrf2 is inhibited in the cytoplasm by the anchor protein Kelch-like ECH-associated protein-1 (Keap1), a cytosolic protein that inhibits Nrf2 signalling by promoting Nrf2 degradation through proteasomal pathway [46]. In the presence of oxidative stress or chemical inducers, Nrf2 is released from Keap1 inhibition, translocates to the nucleus and binds to ARE consensus sequences [47]. Activation of Nrf2 by chemopreventive agents influences the expression of phase II and antioxidative stress enzymes such as heme oxygenase 1 (HO-1) [48]. HO-1 catalyzes the degradation of heme to carbon monoxide, iron and biliverdin and is thought to be essential in cellular defensive mechanisms and is implicated in various pathophysiological conditions such as inflammation, atherosclerosis, neurodegenerative diseases and cancers [49]. Since the first isolation of Nrf2 in 1995 , the function of $\mathrm{Nrf} 2$ has been studied widely [50]. It appears that the most important role of Nrf2 is activating the ARE-mediated anti-oxidative responses [47]. The current understanding of the molecular Nrf2ARE pathway is illustrated in Figure 2 as a schematic presentation of the proposed mechanism by which ARE and its downstream target enzymes are induced upon transcriptional activation $[7,47,51,52]$. Under normal physiological conditions, ROS and other endogenous reactive molecules are also constantly being produced during normal aerobic metabolism, based on numerous experimental evidence, such constitutive gene expression is also thought to be under the regulation of ARE by Nrf2 [47]. Interestingly, many chemopreventive compounds, including ginseng, are inducers of ARE. Additional file 2 lists the studies of ginseng and its extract [53-56] in activating the Nrf2-ARE pathway. 


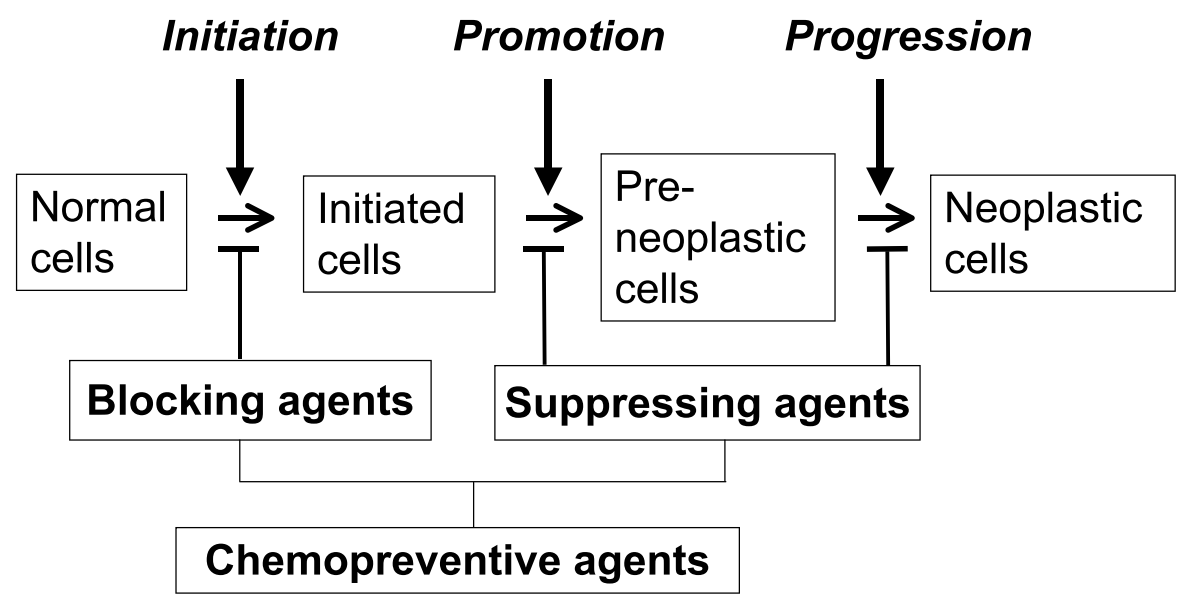

Inflammation \& oxidative stress

Figure 1 Carcinogenesis is a multiple steps process. The initiation step is started by the transformation of the normal cell into a cancer cell (initiated cell). These cells undergo tumour promotion into preneoplastic cells, which progress to neoplastic cells. Inflammation and oxidative stress, together with the accumulation of genetic alterations over a lifetime of patients, will result in the formation of cancer. It is important to take note that in reality, cancer may arise without proceeding through each of these steps. Chemopreventive agents can interfere with different steps of this process. Some agents inhibit metabolic activation of the procarcinogens to their ultimate electrophilic species, or their subsequent interaction with DNA. These agents therefore block tumour initiation (blocking agents). Alternatively, blocking agents can stimulate the detoxification of carcinogens, leading to their excretion from the body. Other agents suppress (suppressing agents) the later steps (promotion and progression). Some agents can act as both blocking and suppressing agents.

\section{Anti-oxidative and anti-inflammatory effects of ginseng} Kim et al. reported that ginseng extract induced the elevation of catalase and superoxide dismutase activities in sedentary male patients [57]. Another study reported significant reduction of oxidative stress biomarkers such as F2-isoprostane and 8-hydroxy-deoxyguanosine in healthy patients after oral administration of ginsenosideenriched Panax quinquefolius (American ginseng) extract [58]. As the study did not measure specific enzymes, it is not clear whether the reduction of these markers was due to the induction of antioxidant enzymes. As an in vivo study found that ginsenosides induced cytochrome (CYP) P450 1A1 which plays an important role in xenobiotic metabolism as well as in carcinogenesis [59], the drug interactions between ginseng and conventional drugs including chemotherapeutic agents should be recognized. It was postulated that ginsenoside competed with aryl hydrocarbons for both the aryl hydrocarbon receptor and CYP1A1, which may explain ginseng's chemopreventive properties [59]. Another study reported that a water extract of ginseng inhibited benzo[a]pyrene ( $\mathrm{BaP})$-induced hepatotoxicity and CYP1A1 expression and reversed the reduction of
GSH content and GST activities induced by BaP in rats [8]. Moreover, various isoforms of phase II gene GSTs were significantly induced by the ginseng extract via activating the Nrf2-ARE pathway. Therefore, the latter in vivo study [8] showed great promise for future studies of ginseng and chemoprevention in chemical-induced animal carcinogenesis models.

The role of Nrf2 is not only implicated in the induction of the antioxidant and phase II genes, but is also involved in anti-inflammation. One of the key transcriptional factors in inflammatory response is the nuclear factor-kappa-B (NF-kB) and many chemopreventive compounds have been reported that those compounds work through activating the Nrf2 pathway also suppressing inflammatory activities [44,60-64]. Glutathione peroxidase 2 (Gpx2) prevented the exacerbation of inflammation induced by cyclooxygenase-2 (COX-2) expression and inflammation driven initiation of carcinogenesis [65]. Various ginsenosides inhibited inducible nitric oxide synthase (iNOS)-induced NO production [66] and down-regulated COX-2 expression [67]. Interestingly, ginseng induced the expression of $\gamma$-glutamylcystein ligase $(\gamma-\mathrm{GCL})$ and enhanced production of GSH 


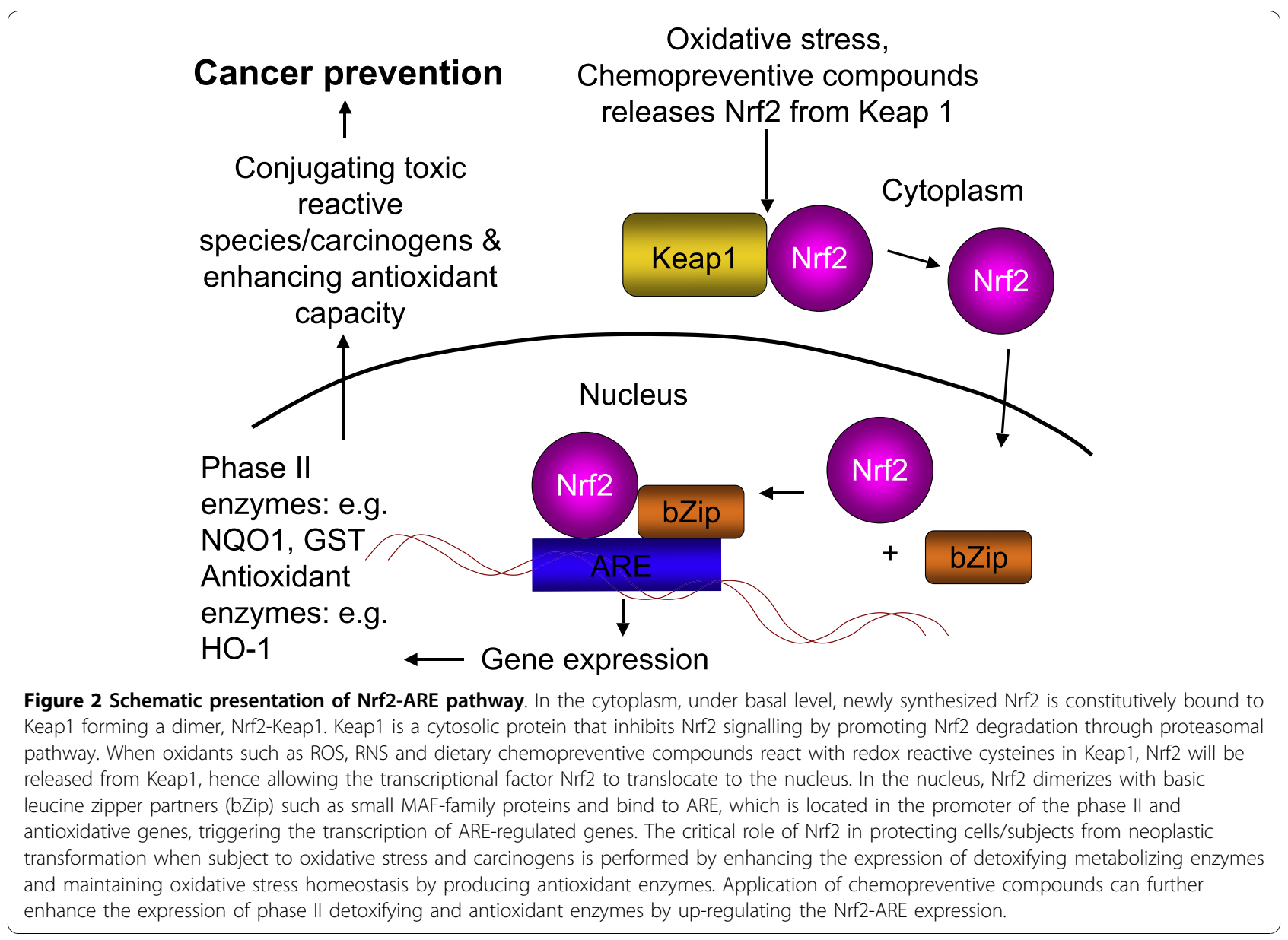

in ginsenoside Rd treated hepatocytes [68]. One would expect that Nrf2 would be induced by ginsenoside Rd as well, however, it was reported that ginsenoside $\mathrm{Rd}$ increased the nuclear level of p65, which is the subunit of NF-kB complex, but not the level of Nrf2 [68]. Such observation is rather uncommon, as other reports have shown that ginsenosides are suppressing NF-kB which will be presented below. Therefore, effects of ginsenoside Rd on NF-kB pathway warrants additional detailed experiment for verification. One of the metabolite of ginsenoside, 20(S)-protopanaxatriol inhibited iNOS and COX-2 expressions through inactivation of NF-kB [69]. Evidence supports the notion that blocking NF-kB is an important target for the control of inflammation and cancer [70,71]. The interplays between Nrf2 and NF-kB signalling pathways were studied in our laboratory with a bioinformatics approach [72] and with an Nrf2-/mouse model $[61,73]$. We found potential common members involved in the crosstalk between Nrf2 and NF-kB signalling pathways, such as some of the upstream mitogen-activated protein kinases (MAPKs). Increasing evidence supports the existing crosstalk between Nrf2 pathway and anti-inflammation
[61,73-77]. It is likely that some of the components in ginseng targeting the Nrf2 pathway and enhancing the expression of ARE-mediated antioxidant and phase II genes would suppress the aberrant inflammatory responses regulated by the NF-kB pathway concomitantly (Figure 3).

\section{Future studies}

In future studies, it would be important to correlate the oxidative stress markers and the development of oxidative stress induced-diseases such as cancer in chemopreventive studies using ginseng/ginseng products. Properly designed long-term clinical studies should be performed to investigate the chemopreventive activities of ginseng, particularly the Nrf2-related antioxidant and phase II detoxifying enzymes as many cancer patients worldwide, have been using ginseng for boosting the immunity or general well-being during chemotherapy, radiotherapy or post-surgery.

\section{Conclusion}

The anti-cancer and chemopreventive actions of ginseng could be exerted through activating the Nrf2 anti-oxidative 


\section{Role of Nrf2 in Chemoprevention}

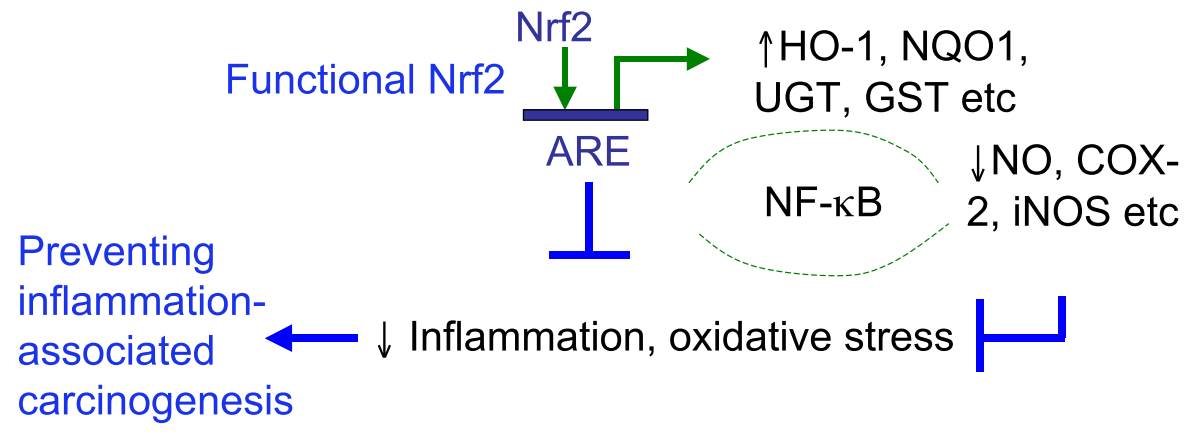

\section{Dysfunctional $\rightarrow$ Prolonged inflammation, oxidative stress Nrf2 \& genetic instability}

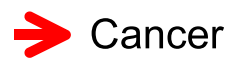

Figure 3 A simplified illustration showing the role of $\mathrm{Nrf2}$ in anti-oxidative and anti-inflammatory pathways preventing carcinogenesis. Upon stimulation by ROS, RNS (having negative effects in subjects) and chemopreventive compounds (having positive effects in subjects), Nrf2 is activated and NF-kB pathways can also be mediated concurrently, such multiple interactions allow chemopreventive compounds, including ginseng, to exert their beneficial cancer preventive and therapeutic effects.

and anti-inflammatory pathways. Further studies on the effects of ginseng in Nrf2-mediated induction of phase II/ antioxidant enzymes would elucidate the action mechanism of ginseng in cancer chemoprevention.

\section{Additional material}

Additional file 1: Clinical studies of ginseng Chinese medicine products as adjuvant therapy to cancer treatments.

Additional file 2: Preclinical studies on ginseng and its extracts showing molecular activities on Nrf2 activation for potential chemopreventive use.

\begin{abstract}
Abbreviations
Nrf2 (NFE2L2): Nuclear factor (erythroid-derived 2)-like 2; ARE: Antioxidant responsive element; CNKI: Chinese National Knowledge Infrastructure; ROS: Reactive oxygen species; RNS: Reactive nitrogen species; GSH: Glutathione; GST: Glutathione S-transferase; UGT: Uridine-diphospho-

glucuronosyltransferases; Keap1: Kelch-like ECH-associated protein-1; HO-1: Heme oxygenase 1; CYP: Cytochrome; BaP: Benzo[a]pyrene; NF-kB: Nuclear factor-kappa-B; Gpx2: Glutathione peroxidase 2; COX-2: Cyclooxygenase-2; iNOS: Inducible nitric oxide synthase; $\gamma$-GCL: $\gamma$-glutamylcystein ligase; MAPKs: Mitogen-activated protein kinases; bZip: Basic leucine zipper partners; GSP: Ginseng polysaccharides; KPS: Karnofsky Performance Status Scale; NPC: Nasopharyngeal carcinoma; RT: Radiotherapy; NK: Natural killer; LAK: Lymphocyte activated killer; NQO1: NADPH: quinone oxidoreductase 1; AKR: Aldo-keto reductases.
\end{abstract}

\section{Acknowledgements}

This work was funded by the Institutional Funds to ANTK. Our appreciation is extended to QW's laboratory for the assistance in obtaining some of the primary literatures. QW received a scholarship from the China Scholarship Council and Beijing University of Chinese Medicine (China).

\section{Author details}

${ }^{1}$ Center for Cancer Prevention Research, Ernest Mario School of Pharmacy, Rutgers, the State University of New Jersey, USA. ${ }^{2}$ Department of Pharmaceutics, Ernest Mario School of Pharmacy, Rutgers, the State University of New Jersey, USA. ${ }^{3}$ Department of Pharmaceutics, School of Chinese Materia Medica, Beijing University of Chinese Medicine, Beijing, China.

\section{Authors' contributions}

CLLS planned this review. CLLS and QW performed the literature searches and drafted the manuscript. ANTK supervised the review process and revised the manuscript. All authors read and approved the final version of the manuscript.

\section{Competing interests}

The authors declare that they have no competing interests.

Received: 22 April 2010 Accepted: 27 October 2010

Published: 27 October 2010

\section{References}

1. Gillis CN: Panax ginseng pharmacology: a nitric oxide link? Biochem Pharmacol 1997, 54(1):1-8.

2. Yue PY, Mak NK, Cheng YK, Leung KW, Ng TB, Fan DT, Yeung HW, Wong RN: Pharmacogenomics and the Yin/Yang actions of ginseng: antitumor, angiomodulating and steroid-like activities of ginsenosides. Chin Med 2007, 2:6.

3. Helms S: Cancer prevention and therapeutics: Panax ginseng. Altern Med Rev 2004, 9(3):259-274.

4. Saita $T$, Katano M, Matsunaga $H$, Kouno I, Fujito $H$, Mori M: Screening of polyacetylenic alcohols in crude drugs using the ELISA for panaxytriol. Biol Pharm Bull 1995, 18(7):933-937.

5. Matsunaga H, Saita T, Nagumo F, Mori M, Katano M: A possible mechanism for the cytotoxicity of a polyacetylenic alcohol, panaxytriol: inhibition of mitochondrial respiration. Cancer Chemother Pharmacol 1995, 35(4):291-296.

6. Yun TK: Panax ginseng-a non-organ-specific cancer preventive? Lancet Oncol 2001, 2(1):49-55. 
7. Li W, Kong AN: Molecular mechanisms of Nrf2-mediated antioxidant response. Mol Carcinog 2009, 48(2):91-104.

8. Gum Sl, Jo SJ, Ahn SH, Kim SG, Kim JT, Shin HM, Cho MK: The potent protective effect of wild ginseng (Panax ginseng C.A. Meyer) against benzo[alpha]pyrene-induced toxicity through metabolic regulation of CYP1A1 and GSTs. J Ethnopharmacol 2007, 112(3):568-576.

9. $\quad \mathrm{Ng}$ F, Yun H, Lei X, Danishefsky SJ, Fahey J, Stephenson K, Flexner C, Lee L: (3R, 9R, 10R)-Panaxytriol: A molecular-based nutraceutical with possible application to cancer prevention and treatment. Tetrahedron Lett 2008, 49(50):7178-7179.

10. Hwang YP, Jeong HG: Ginsenoside Rb1 protects against 6hydroxydopamine-induced oxidative stress by increasing heme oxygenase-1 expression through an estrogen receptor-related PI3K/Akt/ Nrf2-dependent pathway in human dopaminergic cells. Toxicol Appl Pharmacol 2010, 242(1):18-28.

11. Morris CA, Avorn J: Internet marketing of herbal products. Jama 2003, 290(11):1505-1509.

12. DeAngelis $C D$, Fontanarosa PB: Drugs alias dietary supplements. Jama 2003, 290(11):1519-1520.

13. Dietz BM, Liu D, Hagos GK, Yao P, Schinkovitz A, Pro SM, Deng S, Farnsworth NR, Pauli GF, van Breemen RB, Bolton JL: Angelica sinensis and its alkylphthalides induce the detoxification enzyme NAD(P)H: quinone oxidoreductase 1 by alkylating Keap1. Chem Res Toxicol 2008, 21(10):1939-1948.

14. Yun TK: Experimental and epidemiological evidence on non-organ specific cancer preventive effect of Korean ginseng and identification of active compounds. Mutat Res 2003, 523-524:63-74

15. Shibata S: Chemistry and cancer preventing activities of ginseng saponins and some related triterpenoid compounds. J Korean Med SC 2001, 16(Suppl):S28-37.

16. Chang YS, Seo EK, Gyllenhaal C, Block KI: Panax ginseng: a role in cancer therapy? Integr Cancer Ther 2003, 2(1):13-33.

17. Jia L, Zhao Y, Liang XJ: Current evaluation of the millennium phytomedicine- ginseng (II): Collected chemical entities, modern pharmacology, and clinical applications emanated from traditional Chinese medicine. Curr Med Chem 2009, 16(22):2924-2942.

18. Xiang YZ, Shang HC, Gao XM, Zhang BL: A comparison of the ancient use of ginseng in traditional Chinese medicine with modern pharmacological experiments and clinical trials. Phytother Res 2008, 22(7):851-858

19. Qi LW, Wang CZ, Yuan CS: American ginseng: potential structure-function relationship in cancer chemoprevention. Biochem Pharmacol 2010, 80(7):947-954

20. Ni W, Zhang X, Wang B, Chen Y, Han H, Fan Y, Zhou Y, Tai G: Antitumor activities and immunomodulatory effects of ginseng neutral polysaccharides in combination with 5-fluorouracil. J Med Food 2010, 13(2):270-277.

21. Cheng H, Li S, Fan Y, Gao X, Hao M, Wang J, Zhang X, Tai G, Zhou Y: Comparative studies of the antiproliferative effects of ginseng polysaccharides on HT-29 human colon cancer cells. Med Oncol 2010

22. Zeng Y: Adjunctive therapy of Ginseng Polysaccharide for lung cancer. China Pharmaceuticals 2001, 10(6):31-32

23. Fu W, Chen L, Huang S, Zou H: The role of Panax ginseng polysaccharide injection in chemotherapy of patients with ovarian cancer. Pharm Care \& Res 2005, 5(2):169-171.

24. Xie F, Zeng Z, Huang $H$, Zhao C, Lu T: Clinical observation on nasopharyngeal carcinoma treated with combined therapy of radiotherapy and ginseng polysaccharide injection. Zhongguo Zhong $X_{i} Y_{i}$ Jie He Za Zhi 2001, 21(5):332-334.

25. Liu J, Sun L, Zhao Y, Zhou T, Zhang J, Sui G, Wu J, Zhou J, Fu L, Lu Q, Liu G, Hui M: Clinical phase II study on immunoimprovement of patients with breast cancer treated by Shenyi capsule. Chin J Clin Oncol 2000, 27(7):534-536.

26. Liu S, Sun L, Ban L, Zhou T: Ginsenoside Rg3 capsules combined NP regimen in the treatment of advanced non-small cell lung cancer. Chin Clin Oncol 2007, 12(11):847-849.

27. Wang $\mathrm{H}, \mathrm{Li} X$ : The application of shengmai injection in malignant tumor. Mod Chin Med 2003, 3: 16-17.

28. Berenblum I, Armuth V: Two independent aspects of tumor promotion. Biochim Biophys Acta 1981, 651(1):51-63.
29. Heidelberger C, Freeman AE, Pienta RJ, Sivak A, Bertram JS, Casto BC, Dunkel VC, Francis MW, Kakunaga T, Little JB, Schechtman LM: Cell transformation by chemical agents-a review and analysis of the literature. A report of the U.S. Environmental Protection Agency GeneTox Program. Mutat Res 1983, 114(3):283-385.

30. Weinberg F, Chandel NS: Reactive oxygen species-dependent signaling regulates cancer. Cell Mol Life Sci 2009, 66(23):3663-3673.

31. Mantovani A, Allavena P, Sica A, Balkwill F: Cancer-related inflammation. Nature 2008, 454(7203):436-444

32. Aggarwal BB, Shishodia S: Molecular targets of dietary agents for prevention and therapy of cancer. Biochem Pharmacol 2006, 71(10):1397-1421.

33. Juge N, Mithen RF, Traka M: Molecular basis for chemoprevention by sulforaphane: a comprehensive review. Cell Mol Life Sci 2007, 64(9):1105-1127.

34. Wattenberg LW: Chemoprevention of cancer. Cancer Res 1985, 45(1):1-8.

35. Hsu CH, Cheng AL: Clinical studies with curcumin. Adv Exp Med Biol 2007, 595:471-480.

36. Hatcher H, Planalp R, Cho J, Torti FM, Torti SV: Curcumin: from ancient medicine to current clinical trials. Cell Mol Life Sci 2008, 65(11):1631-1652

37. XU C, Li CY, Kong AN: Induction of phase I, II and III drug metabolism/ transport by xenobiotics. Arch Pharm Res 2005, 28(3):249-268.

38. Valgimigli L, lori R: Antioxidant and pro-oxidant capacities of ITCs. Environ Mol Mutagen 2009, 50(3):222-237.

39. Yu S, Kong AN: Targeting carcinogen metabolism by dietary cancer preventive compounds. Curr Cancer Drug Targets 2007, 7(5):416-424.

40. Shen G, Kong AN: Nrf2 plays an important role in coordinated regulation of Phase II drug metabolism enzymes and Phase III drug transporters. Biopharm Drug Dispos 2009, 30(7):345-355.

41. Yuan $J H$, Li YQ, Yang $X Y$ : Inhibition of epigallocatechin gallate on orthotopic colon cancer by upregulating the Nrf2-UGT1A signal pathway in nude mice. Pharmacology 2007, 80(4):269-278.

42. Yuan JH, Li YQ, Yang $X Y$ : Protective effects of epigallocatechin gallate on colon preneoplastic lesions induced by 2-amino-3-methylimidazo[4,5-f ] quinoline in mice. Mol Med 2008, 14(9-10):590-598.

43. Kwak MK, Kensler TW: Targeting NRF2 signaling for cancer chemoprevention. Toxicol Appl Pharmacol 2010, 244(1):66-76.

44. Khor TO, Yu S, Kong AN: Dietary cancer chemopreventive agents targeting inflammation and Nrf2 signaling pathway. Planta Med 2008, 74(13):1540-1547.

45. Nair S, Li W, Kong AN: Natural dietary anti-cancer chemopreventive compounds: redox-mediated differential signaling mechanisms in cytoprotection of normal cells versus cytotoxicity in tumor cells. Acto Pharmacol sin 2007, 28(4):459-472.

46. Katoh Y, lida K, Kang Ml, Kobayashi A, Mizukami M, Tong Kl, McMahon M, Hayes JD, Itoh K, Yamamoto M: Evolutionary conserved N-terminal domain of Nrf2 is essential for the Keap1-mediated degradation of the protein by proteasome. Arch Biochem Biophys 2005, 433(2):342-350.

47. Nguyen T, Nioi P, Pickett CB: The Nrf2-antioxidant response element signaling pathway and its activation by oxidative stress. J Biol Chem 2009, 284(20):13291-13295.

48. Yuan X, Xu C, Pan Z, Keum YS, Kim JH, Shen G, Yu S, Oo KT, Ma J, Kong AN Butylated hydroxyanisole regulates ARE-mediated gene expression via Nrf2 coupled with ERK and JNK signaling pathway in HepG2 cells. Mol Carcinog 2006, 45(11):841-850.

49. Abraham NG, Kappas A: Pharmacological and clinical aspects of heme oxygenase. Pharmacol Rev 2008, 60(1):79-127.

50. Moi P, Chan K, Asunis I, Cao A, Kan YW: Isolation of NF-E2-related factor 2 (Nrf2), a NF-E2-like basic leucine zipper transcriptional activator that binds to the tandem NF-E2/AP1 repeat of the beta-globin locus control region. Proc Natl Acad Sci USA 1994, 91(21):9926-9930.

51. Kwak MK, Wakabayashi N, Kensler TW: Chemoprevention through the Keap1-Nrf2 signaling pathway by phase 2 enzyme inducers. Mutat Res 2004, 555(1-2):133-148.

52. Jeong WS, Jun M, Kong AN: Nrf2: a potential molecular target for cancer chemoprevention by natural compounds. Antioxid Redox Signal 2006, 8(12):99-106.

53. Lee LS, Stephenson KK, Fahey JW, Parsons TL, Lietman PS, Andrade AS, Lei $X$, Yun $H$, Soon GH, Shen P, Danlshefsky S, Flexner C: Induction of chemoprotective phase 2 enzymes by ginseng and its components. Planta Med 2009, 75(10):1129-1133. 
54. Halim M, Yee DJ, Sames D: Imaging induction of cytoprotective enzymes in intact human cells: coumberone, a metabolic reporter for human AKR1C enzymes reveals activation by panaxytriol, an active component of red ginseng. J Am Chem Soc 2008, 130(43):14123-14128.

55. Park SH, Jang JH, Chen CY, Na HK, Surh YJ: A formulated red ginseng extract rescues PC12 cells from PCB-induced oxidative cell death through Nrf2-mediated upregulation of heme oxygenase-1 and glutamate cysteine ligase. Toxicology 2010, 278(1):131-139.

56. Li J, Ichikawa T, Jin $Y$, Hofseth $L$, Nagarkatti $P$, Nagarkatti $M$, Windust $A$ Cui T: An essential role of Nrf2 in American ginseng-mediated antioxidative actions in cardiomyocytes. J Ethnopharmacol 2010, 130(2):222-230.

57. Kim SH, Park KS, Chang MJ, Sung JH: Effects of Panax ginseng extract on exercise-induced oxidative stress. J Sports Med Phys Fitness 2005, 45(2):178-182.

58. Lee LS, Wise SD, Chan C, Parsons TL, Flexner C, Lietman PS: Possible differential induction of phase 2 enzyme and antioxidant pathways by american ginseng, Panax quinquefolius. J Clin Pharmacol 2008, 48(5):599-609.

59. Wang Y, Ye X, Ma Z, Liang Q, Lu B, Tan H, Xiao C, Zhang B, Gao Y: Induction of cytochrome P450 1A1 expression by ginsenoside Rg1 and Rb1 in HepG2 cells. Eur J Pharmacol 2008, 601(1-3):73-78.

60. Kim J, Cha YN, Surh YJ: A protective role of nuclear erythroid 2-related factor-2 (Nrf2) in inflammatory disorders. Mutat Res 2010, 690(1-2):12-23.

61. Lin W, Wu RT, Wu T, Khor TO, Wang H, Kong AN: Sulforaphane suppressed LPS-induced inflammation in mouse peritoneal macrophages through Nrf2 dependent pathway. Biochem Pharmacol 2008, 76(8):967-973.

62. Liu H, Dinkova-Kostova AT, Talalay P: Coordinate regulation of enzyme markers for inflammation and for protection against oxidants and electrophiles. Proc Natl Acad Sci USA 2008, 105(41):15926-15931.

63. Dinkova-Kostova AT, Liby KT, Stephenson KK, Holtzclaw WD, Gao X, Suh N, Williams C, Risingsong R, Honda T, Gribble GW, Sporn MB, Talalay P: Extremely potent triterpenoid inducers of the phase 2 response: correlations of protection against oxidant and inflammatory stress. Proc Natl Acad Sci USA 2005, 102(12):4584-4589.

64. Ahn YH, Hwang Y, Liu H, Wang XJ, Zhang Y, Stephenson KK, Boronina TN, Cole RN, Dinkova-Kostova AT, Talalay P, Cole PA: Electrophilic tuning of the chemoprotective natural product sulforaphane. Proc Natl Acad SCi USA 2010, 107(21):9590-9595.

65. Banning A, Florian S, Deubel S, Thalmann S, Muller-Schmehl K, Jacobasch G, Brigelius-Flohe R: GPx2 counteracts PGE2 production by dampening COX-2 and mPGES-1 expression in human colon cancer cells. Antioxid Redox Signal 2008, 10(9):1491-1500.

66. Park YC, Lee CH, Kang HS, Kim KW, Chung HT, Kim HD: Ginsenoside-Rh1 and $\mathrm{Rh} 2$ inhibit the induction of nitric oxide synthesis in murine peritoneal macrophages. Biochem Mol Biol Int 1996, 40(4):751-757.

67. Surh YJ, Na HK, Lee JY, Keum YS: Molecular mechanisms underlying antitumor promoting activities of heat-processed Panax ginseng C.A. Meyer. $J$ Korean Med Sci 2001, 16(Suppl):S38-41.

68. Kim ND, Pokharel YR, Kang KW: Ginsenoside Rd enhances glutathione levels in H4IIE cells via NF-kappaB-dependent gamma-glutamylcysteine ligase induction. Pharmazie 2007, 62(12):933-936.

69. Oh GS, Pae HO, Choi BM, Seo EA, Kim DH, Shin MK, Kim JD, Kim JB, Chung HT: 20(S)-Protopanaxatriol, one of ginsenoside metabolites, inhibits inducible nitric oxide synthase and cyclooxygenase-2 expressions through inactivation of nuclear factor-kappaB in RAW 264.7 macrophages stimulated with lipopolysaccharide. Cancer Lett 2004, 205(1):23-29.

70. Darnell JE: Transcription factors as targets for cancer therapy. Nat ReV Cancer 2002, 2(10):740-749.

71. Richmond A: Nf-kappa B, chemokine gene transcription and tumour growth. Nat Rev Immunol 2002, 2(9):664-674.

72. Nair S, Doh ST, Chan JY, Kong AN, Cai L: Regulatory potential for concerted modulation of Nrf2- and Nfkb1-mediated gene expression in inflammation and carcinogenesis. Br J Cancer 2008, 99(12):2070-2082.

73. Wang H, Khor TO, Saw CL, Lin W, Wu T, Huang Y, Kong AN: Role of Nrf2 in suppressing LPS-induced inflammation in mouse peritoneal macrophages by polyunsaturated fatty acids docosahexaenoic acid and eicosapentaenoic acid. Mol Pharm 2010.

74. Kuang X, Scofield VL, Yan M, Stoica G, Liu N, Wong PK: Attenuation of oxidative stress, inflammation and apoptosis by minocycline prevents retrovirus-induced neurodegeneration in mice. Brain Res 2009, 1286:174-184.

75. Cho HY, Gladwell W, Wang X, Chorley B, Bell D, Reddy SP, Kleeberger SR: Nrf2-regulated PPAR\{gamma\} expression is critical to protection against acute lung injury in mice. Am J Respir Crit Care Med 2010, 182(2):170-182.

76. Saw $C L$, Huang $Y$, Kong AN: Synergistic anti-inflammatory effects of low doses of curcumin in combination with polyunsaturated fatty acids: docosahexaenoic acid or eicosapentaenoic acid. Biochem Pharmacol 2010, 79(3):421-430.

77. Cheung KL, Khor TO, Kong AN: Synergistic effect of combination of phenethyl isothiocyanate and sulforaphane or curcumin and sulforaphane in the inhibition of inflammation. Pharm Res 2009, 26(1):224-231.

doi:10.1186/1749-8546-5-37

Cite this article as: Saw et al: Anti-cancer and potential

chemopreventive actions of ginseng by activating Nrf2 (NFE2L2) antioxidative stress/anti-inflammatory pathways. Chinese Medicine 2010 5:37.

\section{Submit your next manuscript to BioMed Central and take full advantage of:}

- Convenient online submission

- Thorough peer review

- No space constraints or color figure charges

- Immediate publication on acceptance

- Inclusion in PubMed, CAS, Scopus and Google Scholar

- Research which is freely available for redistribution

Submit your manuscript at www.biomedcentral.com/submit
C Biomed Central 